\title{
The effect of implementation strength of basic emergency obstetric and newborn care (BEmONC) on facility deliveries and the met need for BEmONC at the primary health care level in Ethiopia
}

Gizachew Tadele Tiruneh ${ }^{1 *}$ D, Ali Mehryar Karim², Bilal lqbal Avan ${ }^{3}$, Nebreed Fesseha Zemichael ${ }^{1}$, Tewabech Gebrekiristos Wereta ${ }^{1}$, Deepthi Wickremasinghe ${ }^{3}$, Zinar Nebi Keweti ${ }^{1}$, Zewditu Kebede ${ }^{4}$ and Wuleta Aklilu Betemariam ${ }^{1}$

\begin{abstract}
Background: Basic emergency obstetric and newborn care (BEmONC) is a primary health care level initiative promoted in low- and middle-income countries to reduce maternal and newborn mortality. Tailored support, including BEmONC training to providers, mentoring and monitoring through supportive supervision, provision of equipment and supplies, strengthening referral linkages, and improving infection-prevention practice, was provided in a package of interventions to 134 health centers, covering 91 rural districts of Ethiopia to ensure timely BEmONC care. In recent years, there has been a growing interest in measuring program implementation strength to evaluate public health gains. To assess the effectiveness of the BEmONC initiative, this study measures its implementation strength and examines the effect of its variability across intervention health centers on the rate of facility deliveries and the met need for BEmONC.

Methods: Before and after data from 134 intervention health centers were collected in April 2013 and July 2015. A BEmONC implementation strength index was constructed from seven input and five process indicators measured through observation, record review, and provider interview; while facility delivery rate and the met need for expected obstetric complications were measured from service statistics and patient records. We estimated the dose-response relationships between outcome and explanatory variables of interest using regression methods.
\end{abstract}

Results: The BEmONC implementation strength index score, which ranged between zero and 10, increased statistically significantly from 4.3 at baseline to 6.7 at follow-up $(p<.05)$. Correspondingly, the health center delivery rate significantly increased from $24 \%$ to $56 \%(p<.05)$. There was a dose-response relationship between the explanatory and outcome variables. For every unit increase in BEmONC implementation strength score there was a corresponding average of 4.5 percentage points (95\% confidence interval: 2.1-6.9) increase in facility-based deliveries; while a higher score for BEmONC implementation strength of a health facility at follow-up was associated with a higher met need.

(Continued on next page)

\footnotetext{
* Correspondence: gizachew_tadele@et.jsi.com; ali_karim@jsi.com

'The Last Ten Kilometers (L10K) Project, JSI Research \& Training Institute, Inc.,

Addis Ababa, Ethiopia

${ }^{2}$ The Last Ten Kilometers (L1OK) Project, JSI Research \& Training Institute, Inc.,

Washington DC, USA

Full list of author information is available at the end of the article
}

(c) The Author(s). 2018 Open Access This article is distributed under the terms of the Creative Commons Attribution 4.0 International License (http://creativecommons.org/licenses/by/4.0/), which permits unrestricted use, distribution, and

reproduction in any medium, provided you give appropriate credit to the original author(s) and the source, provide a link to the Creative Commons license, and indicate if changes were made. The Creative Commons Public Domain Dedication waiver (http://creativecommons.org/publicdomain/zero/1.0/) applies to the data made available in this article, unless otherwise stated. 
(Continued from previous page)

Conclusion: The BEmONC initiative was effective in improving institutional deliveries and may have also improved the met need for BEmONC services. The BEmONC implementation strength index can be potentially used to monitor the implementation of BEmONC interventions.

Keywords: Basic emergency obstetric and newborn care (BEmONC), Emergency obstetric care (EmONC), Ethiopia, Implementation strength, Life-saving interventions, Low- and middle-income countries (LMIC), Maternal and newborn health, Primary health care, Rural health centers

\section{Background}

Globally, about $45 \%$ of maternal deaths and $36 \%$ of neonatal deaths occur during the first $24 \mathrm{~h}$ after birth $[1,2]$. Maternal and newborn deaths related to the perinatal period are largely preventable, and most life-threatening conditions are treatable if skilled health care is provided during the intrapartum and early postnatal periods [3-5] at the primary health care level [6-8]. However, in lowand middle-income countries (LMIC), where maternal and neonatal mortality is high, the availability, accessibility, and use of proven life-saving interventions for the treatment of obstetric complications are low $[9,10]$.

Ethiopia made progress in improving maternal and child health during the Millennium Development Goal era from 1990 to 2015. The maternal mortality rate (MMR) dropped by $72 \%$ from 1250 to 353 per 100,000 live births, while child mortality decreased by two-thirds from 205 to 59 per 1000 live births $[10,11]$. The reduction in the neonatal mortality rate (NMR) has been slow during that period and is currently 28 deaths per 1000 live births, accounting for $47 \%$ of all under- 5 years mortality [11]. Despite this decline, Ethiopia's MMR is still regarded as among the highest in the world [10]. Moreover, the coverage of skilled attendance at birth and the met need for obstetric and newborn care are low [12, 13]. Committed to contribute toward achieving the maternal and newborn survival-related Sustainable Development Goals (i.e., to reduce global MMR to less than 70 per 100,000 live births and NMR to at least as low as 12 per 1000 live births by 2030 [14, 15], the Health Sector Transformation Plan (HSTP) of Ethiopia targets to reduce MMR to 199 per 100,000 live births and NMR to 10 per 1000 live births by 2020 [16].

One of the key strategies promoted to reduce both maternal and newborn mortality in LMIC is the timely access to comprehensive emergency obstetric and newborn care (CEmONC) [5, 17], with the provision of at least the basic emergency obstetric and newborn care (BEmONC) (see Box 1 for definition) at the primary health care level of a country's health system [17]. To track progress in monitoring this strategy, the availability of BEmONC services, the proportion of all live births taking place in facilities, and the met need for EmONC are among the key indicators that have been developed for the primary care level [17] (Table 1).

A systematic review of studies using quasi-experimental, observational, and ecological designs demonstrates evidence of the effectiveness of EmONC interventions in reducing maternal mortality in LMIC [3]. A recent intervention study in Ethiopia suggests that upgrading facilities to provide life-saving interventions decreased the MMR and improved facility delivery rate [18]. Similar studies elsewhere demonstrate that implementation of EmONC has significantly improved the facility delivery and the met need for EmONC [19].

Despite the availability of evidence of the efficacy of life-saving interventions to avert high rates of maternal and newborn deaths $[5,20]$, there is little understanding of how to deliver those interventions effectively [21-23]. Accordingly, intervention strategies need to be properly evaluated to identify successful, evidence-based, low-cost interventions, or implementation approaches that can be scaled-up, to promote their sustainable integration into health systems, and to ensure accountability to donors for public health gains [22-24]. Measuring the strength of program implementation is one of the evaluation approaches that helps to understand which packages of

\section{Table 1 Definition of BEmONC}

Emergency obstetric and newborn care (EmONC) is defined as a set of life-saving interventions, that treat the major obstetric and newborn causes of morbidity and mortality. To assess the level of care, these functions are classified as basic EmONC (BEmONC) or comprehensive EmONC (CEmONC) levels of care.

BEmONC services comprise:

1) administration of parenteral antibiotics to prevent puerperal infection or treat abortion complications;

2) administration of parenteral anticonvulsants for treatment of eclampsia and preeclampsia;

3) administration of parenteral uterotonic drugs for postpartum

hemorrhage;

4) manual removal of the placenta;

5) assisted vaginal delivery (vacuum extractions);

6) removal of retained products of conception; and

7) neonatal resuscitation

If a facility has provided all seven key BEmONC functions in the last

3 months, it is called a BEmONC facility.

CEmONC services comprise caesarean sections and blood transfusions, in addition to BEmONC functions.

Source: WHO, 2009 [17] 
interventions are delivered effectively (and which are not) and why some programs are effective and attribute outcomes to program implementation characteristics [23, 25, 26]. However, in LMIC, there is a gap between knowledge of proven interventions and gains through implementation variations [22].

Strengthening the health care system to provide $\mathrm{BEmONC}$ is a key priority for providing life-saving services, especially in rural areas [12, 18, 27]. The Government of Ethiopia took an initiative to improve access to BEmONC services by upgrading the capability of health centers at the country's primary health care level. Measuring the implementation strength of the BEmONC package of interventions (i.e., the degree of functionality of the different aspects of BEmONC) at the health centers in Ethiopia is essential to understanding which aspects of BEmONC care improved (and which did not). Moreover, it also helped identify whether the improvement in BEmONC was associated with an increase in utilization of services for critical maternal and newborn care practices. As such, the implementation variability of BEmONC initiatives can be studied with the concept of implementation strength to explore the association between the implementation strength and utilization of facility delivery. It is hypothesized that higher implementation strength of the BEmONC score of primary level facilities is associated with the utilization of facility deliveries and the met need for BEmONC.

Most previous studies have focused on changes in the uptake of EmONC, the variability of program inputs, and effectiveness of special interventions like the implementation of transport systems, emergency loans, community financing, communications, or various combinations of these elements $[18,19,28-30]$ on the uptake of facility delivery and the met need for EmONC, without distinguishing the level of care. Moreover, there is little programmatic evidence of how implementation variability affects the uptake of maternal and newborn health services at the primary health care level. Thus, this study examines the effectiveness of the BEmONC initiative by analyzing the effect of facility inputs and the process of service delivery as implementation strength index score on the rate of facility deliveries and the met need for BEmONC in rural health centers of Ethiopia.

\section{Study settings}

The Ethiopian primary health care system employs decentralized governance structures where regions are divided into zones, which are internally divided into districts. To respond to its population needs, the Government of Ethiopia has restructured its health service into a threetier system of care: primary, secondary, and tertiary [16]. Primary level health care, the major platform for health service delivery at the grassroots level, in a rural district in
Ethiopia consists of one primary hospital with four or five primary health care units (PHCUs). Each PHCU comprises a health center with five satellite health posts serving about 25,000 people in total. Health centers are staffed with health officers, nurses, midwives, and laboratory technicians to provide primarily preventive, curative, inpatient and ambulatory services, treatment of common psychiatric disorders, and dental services.

To reduce the high rate of maternal mortality in Ethiopia, the Government expanded health centers to achieve a target of one health center providing all BEmONC functions for every 25,000 population during the implementation of Health Sector Development Plan IV from 2010 to 2015. Moreover, the country sought to improve access to, and utilization of, BEmONC services by mobilizing communities to encourage pregnant mothers to give birth in health centers, expanding health centers, staffing health centers with midwives to ensure BEmONC services are always available, and providing ambulances to districts to mitigate transportation barriers [31].

However, national evidence shows that most health centers were weak in providing life-saving BEmONC interventions, with only a few facilities providing all BEmONC functions. In most health centers, drugs, equipment, and supplies were missing, the centers were poorly staffed, or staff lacked the skills to apply most BEmONC functions. Moreover, the proportion of facility deliveries and the met need for BEmONC were low [12, 13]. Strengthening health centers to provide all BEmONC functions remains a challenge. This is particularly so in rural health centers [32]. As such, the Federal Ministry of Health has set targets for facility delivery coverage at $90 \%$ and to enable all health centers to provide all BEmONC functions by 2020 [16].

\section{Methods}

\section{The BEmONC initiative}

To upgrade the capability of health centers to provide timely BEmONC, tailored support was provided to 134 health centers, covering 91 rural districts of Ethiopia during the first phase of Ethiopia's BEmONC-strengthening initiative, which was initiated in April 2013. This included BEmONC training to providers, mentoring and monitoring through post-training follow-up, provision of equipment and supplies, strengthening referral linkages, and improving infection-prevention practice.

\section{Study design}

A before and after evaluation for the BEmONC intervention included a cross-sectional survey conducted in April 2013 and July 2015, in 134 rural health centers in 91 districts of four regions: Amhara, Oromia, the Southern National, Nationalities, and Peoples' Region, and Tigray. The effectiveness of the BEmONC initiative was determined by 
the dose-response relationships between BEmONC implementation strength (BIS) of the health centers and the outcomes of interest.

\section{Conceptual framework}

A conceptual framework for measuring BIS was developed through a review of peer-reviewed and gray literature. Organizational structure (i.e., the resources of the health care system) and processes of service delivery are identified as components for measuring implementation strength $[17,25,33,34]$. The structural components, well-documented in the literature, to provide quality $\mathrm{BEmONC}$ are a functioning facility with a skilled health service provider available around the clock and functional and adequate supplies, equipment, drugs, and infrastructure. An effective referral system is also critical to ensure a woman reaches the facility in a timely manner. The core elements of an effective referral system include formalized communication and transport, sufficiently resourced referral centers, active collaboration across all referral levels, protocols for the referrer and receiver, and accountability for providers' performances, coupled with supportive supervision [34]. With regard to the process components, facilities must provide lifesaving interventions in a timely manner to respond to women's needs $[8,17,35,36]$. In addition, the project implementation pathway was analyzed by reviewing project documents and the Project Management Plan. The critical components necessary for measuring BIS in rural health centers to improve the use of critical maternal and newborn care services are 1) facilities' emergency readiness in terms of availability of services, human resources, equipment, and drugs; 2) effective referral; 3) the support system; and 4) adherence to basic life-saving interventions and quality of care (Fig. 1).

\section{Data}

All 134 first-phase intervention health centers were visited during baseline and follow-up surveys. Data were collected through interviews, observation, and a review of patient records and service statistics. Data collectors conducted interviews with the heads of the health centers and health care providers working in the maternity units to gather information on the availability of equipment and supplies, human resources, the performance of BEmONC signal functions, and other maternal and newborn health services. Observations were made to assess the infrastructure and supplies available. Documents were reviewed to gather data on service statistics and patient records, to assess utilization of services for critical maternal, and newborn conditions. The survey questionnaire and the dataset we used for this study are presented as additional files (see Additional files 1 and 2).

Baseline data were collected using paper-based questionnaires and data were entered using Epi Info 7. The quality assurance of data entry was ensured through appropriate skip patterns and allowing only logical values data entry. The data entry was done twice and both entries were validated with each other to eliminate data entry errors. In the follow-up survey, data were captured using the Android mobile application SurveyCTO [37].

\section{Measurements}

The independent variable of interest was BIS, which was measured during the baseline and follow-up surveys as an index using items measuring programmatic input and process indicators listed in Table 2 below. Three of the BEmONC signal functions, namely administration of parenteral uterotonics, administration of parenteral antibiotics, and administration of parenteral $\mathrm{MgSO}_{4}$ were dropped from the calculation of the BIS score because the availability of the drugs necessary for the provision of these functions was already included under indicator number 4 (Table 2).

As the variables are not on the same scale, they were standardized by dividing the observed sum of the individual variable scores values by their standard deviation to make comparisons of variables and then aggregated

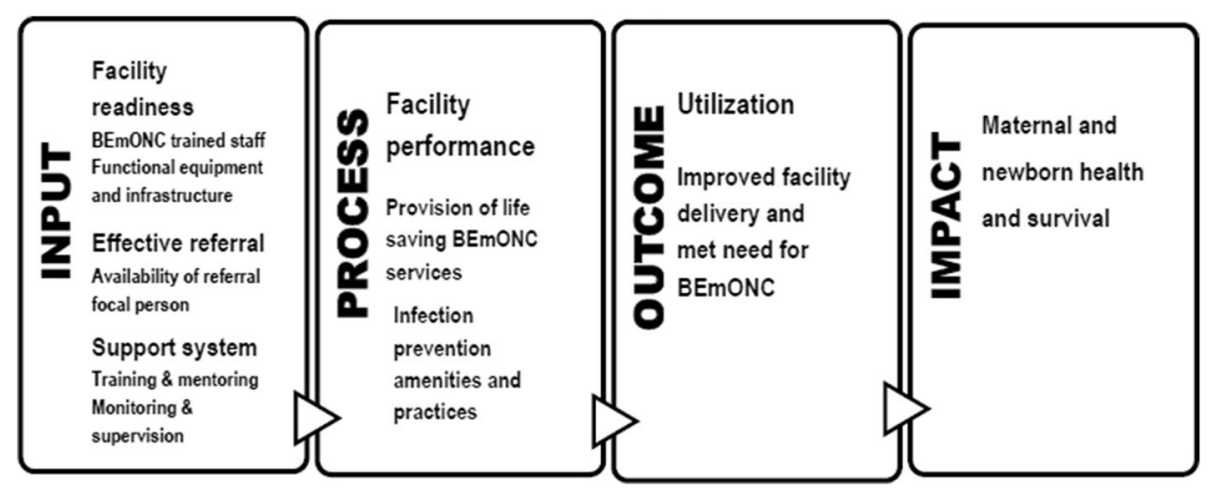

Fig. 1 Conceptual framework: BIS components to improve critical care service utilization at primary facilities 
Table 2 Indicators used to measure BIS index score and their operational definitions

\begin{tabular}{|c|c|c|c|}
\hline SN & Indicators & Definition & Data source \\
\hline I & Input indicators & & \\
\hline 1 & $\begin{array}{l}\text { Number of BEmONC-trained } \\
\text { personnel available }\end{array}$ & $\begin{array}{l}\text { Number of BEmONC-trained providers (health officers, nurses, or midwives) } \\
\text { working in the facility at the time of the survey }\end{array}$ & Interviews with facility heads \\
\hline 2 & $\begin{array}{l}\text { Number of laboratory tests } \\
\text { available }\end{array}$ & $\begin{array}{l}\text { Number of the following laboratory tests: hemoglobin/hematocrit, blood } \\
\text { group, urine analysis, venereal disease research laboratory (VDRL), and HIV } \\
\text { test for PMTCT available in the facility at the time of the data collection }\end{array}$ & Interviews with facility staff \\
\hline 3 & $\begin{array}{l}\text { Number of items of } \\
\text { equipment available }\end{array}$ & $\begin{array}{l}\text { Number of functional equipment, including oxygen concentrator, } \\
\text { sphygmomanometer, vacuum extractor, suction machine, radiant } \\
\text { heater, and Ambu-bag mask available in the facility for provision } \\
\text { of BEmONC care at the time of the survey }\end{array}$ & $\begin{array}{l}\text { Interviews with facility staff } \\
\text { and observation }\end{array}$ \\
\hline 4 & Number of drugs available & $\begin{array}{l}\text { Number of the following drugs: intravenous (IV) uterotonics, IV fluids, } \\
\text { Nifedipine, Hydralazine, IV antibiotics, IV } \mathrm{MgSO}_{4} \text { and calcium gluconate } \\
\text { available in the facility for provision of } \mathrm{BEmONC} \text { services at the time of } \\
\text { the survey }\end{array}$ & $\begin{array}{l}\text { Interviews with facility staff and } \\
\text { observation }\end{array}$ \\
\hline 5 & $\begin{array}{l}\text { Availability of ambulance } \\
\text { services }\end{array}$ & Availability of ambulance service in the facility $24 \mathrm{~h}$ a day & Interviews with facility heads \\
\hline 6 & $\begin{array}{l}\text { Availability of maternity } \\
\text { waiting homes }\end{array}$ & Availability of maternity waiting area/homes in or around the facility & $\begin{array}{l}\text { Interviews with facility head } \\
\text { and observation }\end{array}$ \\
\hline 7 & $\begin{array}{l}\text { Availability of a focal person } \\
\text { for referral }\end{array}$ & $\begin{array}{l}\text { Availability of a designated referral focal person to coordinate in- and } \\
\text { out-referrals } 24 \mathrm{~h} \text { a day in the facility }\end{array}$ & Interviews with facility heads \\
\hline$\|$ & Process indicators & & \\
\hline 8 & $\begin{array}{l}\text { Infection-prevention } \\
\text { amenities and practices }\end{array}$ & $\begin{array}{l}\text { The following infection-prevention amenities and practices were } \\
\text { observed at the time of the survey: clean facility compound, cleaning } \\
\text { done after birth, availability of disinfectant solutions, disinfectant solution } \\
\text { prepared and used correctly, availability of a container for sharps' disposal, } \\
\text { providers practice hand washing, quality mechanism in place for sterilization, } \\
\text { staff use personal protective barriers, availability of a light source for vaginal } \\
\text { procedure, enough physical space, good illumination and ventilation, and } \\
\text { easily washable delivery floor }\end{array}$ & $\begin{array}{l}\text { Interviews with facility staff } \\
\text { and observation }\end{array}$ \\
\hline $9-12$ & $\begin{array}{l}\text { Provision of BEmONC signal } \\
\text { functions }\end{array}$ & $\begin{array}{l}\text { Provision of the following life-saving BEmONC services in the past } 3 \text { months } \\
\text { for the treatment of obstetric complications; 9) removal of retained products } \\
\text { of conception; 10) manual removal of placenta; 11) assisted vaginal birth; } \\
\text { and 12) neonatal resuscitation }\end{array}$ & Interviews with facility staff \\
\hline
\end{tabular}

to obtain the BIS score. Thus, all the variables were given equal weights. The BIS index was recalibrated to range between zero and 10, with a higher score indicating better BIS. Cronbach's alphas were calculated to assess the internal reliability of the 12 items in measuring the underlying construct of BIS. The possible values of alpha range between zero and one, and values exceeding .70 are regarded as acceptable [38, 39]. The Cronbach's alpha for the 12 items was .71.

The programmatic outcome variables of interest were the facility delivery rate and the met need for BEmONC. The facility delivery rate was defined as the proportion of deliveries that took place in health facilities out of the total expected number of births in the catchment area. The expected births were calculated based on information from the catchment projected population-the population estimate of a health center based on the regional population growth rate estimate [40] - and the crude birth rate for the catchment area. This was calculated as the number of deliveries registered in health facilities in the last 12 months divided by the expected number of live births in that period and multiplied by 100 . The facility delivery rate was calculated during the baseline and follow-up surveys. The met need for BEmONC was defined as the proportion of women with direct obstetric complications (including abortion complications, postpartum hemorrhage, obstructed or prolonged labor, and puerperal sepsis) treated at health centers in the last 12 months. It was calculated as the number of women with obstetric complications treated at health centers in the last 12 months divided by the estimated number of women who would have obstetric complications (i.e., 15\% of expected births) [17] and multiplied by 100 . The met need was measured only during the follow-up survey, as the information about obstetric complications was not collected during the baseline survey.

\section{Statistical analysis}

Data were analyzed for both descriptive and inferential statistics using Stata version 14.2 [41]. Descriptive statistics were used to analyze the inputs and process of service delivery. A paired $t$-test was used to test the statistical significance of the changes in the indicators of interest 
between the baseline and follow-up surveys. An internal comparison group analysis was also done to assess doseresponse relationships between BIS and the outcomes of interest, such as whether health centers with higher improvements in BIS were associated with increased facility delivery and the met need for BEmONC. Fixed-effects ordinary least-squares regression was used to assess the dose-response relationship between the changes in BIS found in the follow-up survey, compared with the baseline survey, and the changes in the health center delivery rate during the same period. Because information for the met need was available only at one point in time, during the follow-up survey, the cross-sectional dose-response relationship between BIS and met need was assessed using ordinary least-squares regression. A scatter plot was used to visualize the associations.

\section{Results}

The findings are presented in four sections: 1) change in BEmONC services over time, 2) changes in BIS and service utilization over time, 3) relationship between changes in BIS over time and changes in facility birth, and 4) relationship between changes in BIS over time and the met need for BEmONC at the primary health care level.

\section{Change in BEmONC services over time at the primary health care level in Ethiopia}

Facility input indicators, including the availability of BEmONC-trained providers, availability of essential drugs and equipment, laboratory tests, and facility infrastructure, increased statistically significantly $(p<.05)$ over the study period (Table 3 ). The mean number of BEmONC-trained providers increased significantly from 1.4 at baseline to 2.6 during the follow-up survey ( $p$ $<.05)$. Overall, the average number of laboratory tests available showed significant improvement over the survey periods with urine analyses and VDRL syphilis tests having improved significantly over time; however, hematological tests (hemoglobin and blood group) and HIV tests for PMTCT did not show statistically significant changes over time. Availability of individual drugs in the health centers showed significant positive changes for most drug categories except IV fluids and Nifedipine $(p<.05)$. The largest change was observed for $\mathrm{MgSO}_{4}$, which increased by 65 percentage points; $p<.01$ ) followed by Hydralazine (53 percentage points; $p<.01$ ), and IV antibiotics (21 percentage points; $p<.01)$. Likewise, the availability of medical equipment, including vacuum extractor sets, radiant heaters, and oxygen concentrators, showed significant change. As the values for the availability of IV fluids and sphygmomanometers were already high in the baseline survey, it would be difficult to see much improvement during the follow-up period; however, the availability of an ambulance service and a focal person to coordinate referrals showed significant improvements over the study period.

The average number of infection-prevention amenities showed significant improvement over time (Table 4). The hand-washing practice of providers (42 percentage points increase, $p<.01$ ) and consistent use of personal protective barriers by staff (26 percentage points increase, $p<.01$ ) were among the larger changes seen. Illumination and ventilation of the maternity units significantly decreased over time $(p<.05)$. This might be due to the difference in survey periods, as the follow-up period was in the rainy season; there might be frequent power failures as well as facilities might blind ventilation outlets to warm maternity units.

Statistically, significant improvements were seen in health center performance for removing retained products of conception and assisted vaginal birth. However, there were no statistically significant changes in the performance of manual placenta removal and neonatal resuscitation.

\section{Changes in the BIS and service utilization over time at the primary health care level in Ethiopia}

The BIS score ranged between zero and 10; which increased $(p<.05)$ from 4.3 (ranging from 0 to 8 at baseline) to 6.7 (ranging from 2 to 10 at follow-up) (Table 5). Correspondingly, the health center delivery rate increased $(p<.001)$ from $24 \%$ to $56 \%$. The distribution of health center delivery rates is presented in Fig. 2 below. As shown in the box plot, $50 \%$ of health centers had a delivery rate between 12.9 and 32.3 at baseline and between 37.2 and 71.8 at follow-up; while one $(0.7 \%)$ health center at baseline and $11(8 \%)$ health centers at follow-up had delivery rates above $100 \%$, which might be due to mothers from outside of their catchment area coming to use the service at these health centers.

The met need for BEmONC was found to be $16 \%$ during the follow-up survey. The most frequent obstetric complication observed in this study was abortion complications, which accounted for about half (8.2\%) of the complications managed at health centers in the 12 months prior to the survey. Postpartum hemorrhage (4.7\%), obstructed/prolonged labor (3.0\%), and postpartum sepsis $(0.1 \%)$ account for the remaining half. The complications managed considered for the met need at health centers did not include hypertension/preeclampsia (though provide prereferral $\mathrm{MgSO}_{4}$ and antihypertensive drugs), ectopic pregnancy, and uterine rupture, which are managed at hospitals with CEmONC services.

\section{Relationship between changes in BIS over time and changes in service utilization of facility birth provision at the primary care level}

Improvements in the BIS score over the study period were significantly associated with improvements in health center delivery: for every unit increase in BIS score across 
Table 3 Input indicators measuring BIS at baseline and follow-up in 134 health centers

\begin{tabular}{|c|c|c|c|c|c|}
\hline \multirow[t]{2}{*}{ Indicator } & \multirow[t]{2}{*}{ Baseline } & \multirow[t]{2}{*}{ Follow-up } & \multicolumn{3}{|c|}{ Change between baseline and follow-up } \\
\hline & & & Change & $(95 \% \mathrm{Cl})$ & $p$-value \\
\hline Average number of BEmONC-trained providers & 1.4 & 2.6 & 1.2 & $(0.9,1.5)$ & $<.001$ \\
\hline \multicolumn{6}{|l|}{ Availability of laboratory tests (\%) } \\
\hline Hemoglobin/Hematocrit & 71.6 & 74.6 & 3.0 & $(-0.1,0.1)$ & .466 \\
\hline Blood group & 91.0 & 93.3 & 2.3 & $(-0.0,0.1)$ & .439 \\
\hline Urine analysis & 79.9 & 94.0 & 14.1 & $(0.1,0.2)$ & $<.001$ \\
\hline VDRL for syphilis test & 53.7 & 71.6 & 17.9 & $(0.1,0.3)$ & $<.001$ \\
\hline HIV test for PMTCT & 99.2 & 95.5 & -3.7 & $(-0.1,0.0)$ & .056 \\
\hline Average number of laboratory tests available & 3.9 & 4.3 & 0.4 & $(0.1,0.6)$ & .001 \\
\hline \multicolumn{6}{|l|}{ Availability of equipment (\%) } \\
\hline Sphygmomanometer & 96.3 & 98.5 & 2.2 & $(-0.0,0.1)$ & .256 \\
\hline Oxygen concentrator & 15.7 & 37.3 & 21.6 & $(0.1,0.3)$ & $<.001$ \\
\hline Vacuum extractor (sets) & 37.3 & 74.6 & 37.3 & $(0.3,0.5)$ & $<.001$ \\
\hline Suction machine & 44.8 & 58.2 & 13.4 & $(0.0,0.3)$ & .025 \\
\hline Radiant heater & 33.6 & 57.5 & 23.9 & $(0.1,0.3)$ & $<.001$ \\
\hline Ambu-bag \& masks & 88.8 & 97.8 & 9.0 & $(0.0,0.2)$ & .002 \\
\hline Average number of items of equipment available & 3.2 & 4.2 & 1.0 & $(0.8,1.4)$ & $<.001$ \\
\hline \multicolumn{6}{|l|}{ Availability of drugs (\%) } \\
\hline IV Uterotonics & 31.3 & 98.5 & 67.2 & $(0.6,0.8)$ & $<.001$ \\
\hline IV fluids & 98.5 & 98.5 & 0.0 & $(-0.0,0.0)$ & 1.000 \\
\hline Nifedipine & 62.7 & 56.7 & -6.0 & $(-0.2,0.1)$ & .267 \\
\hline Hydralazine & 35.1 & 88.1 & 53.0 & $(0.4,0.6)$ & $<.001$ \\
\hline IV antibiotics & 78.4 & 99.3 & 20.9 & $(0.1,0.3)$ & $<.001$ \\
\hline IV MgSO4 & 10.4 & 75.4 & 65.0 & $(0.6,0.7)$ & $<.001$ \\
\hline Calcium gluconate & 4.5 & 15.7 & 11.2 & $(0.0,0.2)$ & .002 \\
\hline Average number of drugs available & 3.2 & 5.3 & 2.1 & $(1.9,2.4)$ & $<.001$ \\
\hline Availability of maternity waiting area/ homes (\%) & 31.3 & 73.9 & 42.6 & $(0.4,0.6)$ & $<.001$ \\
\hline Availability ambulance service (\%) & 81.3 & 91.0 & 9.7 & $(0.4,0.9)$ & $<.001$ \\
\hline Availability of referral focal person (\%) & 27.5 & 39.6 & 12.1 & $(2.4,3.0)$ & $<.001$ \\
\hline
\end{tabular}

time, there was a 4.5 percentage points increase in facilitybased deliveries at health centers (Table 6 and Fig. 3). However, some health centers' BIS score declined over time, mainly due to the decline in the availability of medical equipment and infection-prevention amenities.

Relationship between changes in BIS score over time and the met need for BEmONC at the primary care level

During the follow-up survey, facilities with a higher BIS score were associated with a higher met need for BEmONC (Table 7 and Fig. 4). On average, every unit higher BIS score of a facility was associated with 3.1 percentage points higher met need for BEmONC.

\section{Discussion}

Our study is unique in reporting the effect of BIS on programmatic outcomes at the primary level of care.
The variability in BIS across health facilities and time has demonstrated a significant dose-response association with the key program outcomes: for every unit increase in BIS score, there was a corresponding average increase of four to five facility-based delivery rates at the primary health care level. Moreover, a higher BIS score was associated with a higher met need for BEmONC.

This study showed that facility input and process indicators increased significantly from the baseline survey, demonstrating an increased level of readiness for emergencies and management of common obstetric and newborn complications in primary health care facilities. However, some basic interventions like neonatal resuscitation and the manual removal of the placenta did not change significantly, which might be due to the lack of specific technical skills. Accordingly, focused and more intense mentoring and supportive supervision for particular skills, such as 
Table 4 Process indicators measuring BIS at baseline and follow-up in 134 health centers

\begin{tabular}{|c|c|c|c|c|c|}
\hline \multirow[t]{2}{*}{ Indicator } & \multirow[t]{2}{*}{ Baseline } & \multirow[t]{2}{*}{ Follow-up } & \multicolumn{3}{|c|}{ Change between baseline and follow-up } \\
\hline & & & Change & $(95 \% \mathrm{Cl})$ & $p$-value \\
\hline \multicolumn{6}{|l|}{ Practice to infection-prevention measures (\%) } \\
\hline Facility compound clean & 80.5 & 85.8 & 5.3 & $(-0.0,0.2)$ & .262 \\
\hline Cleaning done after attending birth & 85.1 & 93.3 & 8.2 & $(0.0,0.2)$ & .032 \\
\hline Availability of disinfectant solutions & 92.5 & 100 & 7.5 & $(0.0,0.1)$ & .001 \\
\hline Disinfectant solution prepared \& used per standard & 88.0 & 96.3 & 8.3 & $(0.0,0.2)$ & .014 \\
\hline Availability of container for disposing of sharps & 95.5 & 97.8 & 2.3 & $(-0.0,0.1)$ & .256 \\
\hline Providers' practice hand washing & 37.0 & 79.1 & 42.1 & $(0.3,0.5)$ & $<.001$ \\
\hline Quality mechanism in place for sterilization & 63.9 & 79.9 & 16 & $(0.1,0.3)$ & .002 \\
\hline Staff use personal protective barrier & 58.2 & 84.3 & 26.1 & $(0.2,0.4)$ & $<.001$ \\
\hline Availability of light source for vaginal procedure & 53.0 & 62.7 & 9.7 & $(-0.0,0.2)$ & .144 \\
\hline Enough physical space & 66.9 & 64.9 & -2.0 & $(-0.1,0.1)$ & .782 \\
\hline Good illumination and ventilation & 89.5 & 79.9 & -9.6 & $(-0.2,-0.0)$ & .030 \\
\hline Easily washable delivery floor & 70.7 & 77.6 & 6.9 & $(-0.0,0.2)$ & .207 \\
\hline Average number of infection-prevention amenities & 8.7 & 10.0 & 1.3 & $(0.9,1.8)$ & $<.001$ \\
\hline Removal of retained products of conception & 57.5 & 71.6 & 14.1 & $(0.0,0.2)$ & $<.05$ \\
\hline Manual removal of placenta & 72.4 & 75.4 & 3.0 & $(-0.1,0.1)$ & .565 \\
\hline Assisted vaginal birth & 28.4 & 59.0 & 30.6 & $(0.2,0.4)$ & $<.001$ \\
\hline Neonatal resuscitation & 77.6 & 78.4 & 0.8 & $(-0.1,0.1)$ & .873 \\
\hline
\end{tabular}

neonatal resuscitation and the manual removal of the placenta, could be implemented to improve these interventions.

The mean number of skilled birth attendants (midwives, nurses, and health officers) and pharmacy and laboratory professionals working at health centers available at the time of the survey were in line with the minimum requirements [42].

The implementation strength of BEmONC is strongly associated with the improved availability and utilization of obstetric services in the intervention facilities, which ultimately will enhance the uptake of life-saving interventions to tackle the major causes of maternal and neonatal mortality in Ethiopia. This indicates that investment in the BEmONC initiative to upgrade primary level facilities is effective. As such, policymakers and program planners should make additional investments in improving the availability of critical inputs for the provision of BEmONC and closely monitor the process of service delivery at the primary health care level, to improve the utilization of maternal and newborn health services.

Conventionally, the availability of BEmONC signal functions at health facilities is used to monitor BEmONC programs [17]. The BIS can supplement and complement this by providing program input and process indicators that are essential for program managers to plan and monitor the provision of BEmONC services. Moreover, the BIS index predicts the BEmONC initiative outcomes well and has a good internal reliability. Thus, this would help to measure effort over time and gauge improvements of upgrading facilities for the provision of basic life-saving interventions and the effect of this effort on the utilization of maternal services outcomes at the primary level of care.

It should be noted that the BIS index would serve to monitor BEmONC implementation status of a health facility at a glance; but is not suitable for making a programmatic decision. If the BIS index score is at its maximum or near its

Table 5 Changes in mean service utilization rate and BIS score at baseline and follow-up

\begin{tabular}{|c|c|c|c|c|c|}
\hline \multirow[t]{2}{*}{ Indicator } & \multirow{2}{*}{$\begin{array}{l}\text { Baseline } \\
\text { mean (SD) }\end{array}$} & \multirow{2}{*}{$\begin{array}{l}\text { Follow-up } \\
\text { mean (SD) }\end{array}$} & \multicolumn{3}{|c|}{ Change between baseline and follow-up } \\
\hline & & & Mean (SD) & $(95 \% \mathrm{Cl})$ & $p$-value \\
\hline BIS score & $4.3(1.8)$ & $6.7(1.8)$ & $2.5(2.1)$ & $(2.1,2.8)$ & $<.001$ \\
\hline Health center delivery & $23.6(19.6)$ & $56.0(27.6)$ & $32.4(30.8)$ & $(27.1,37.5)$ & $<.001$ \\
\hline Met need for BEmONC & - & $16.0(16.4)$ & - & - & - \\
\hline
\end{tabular}

$\mathrm{a}_{\text {in }} 134$ health centers 


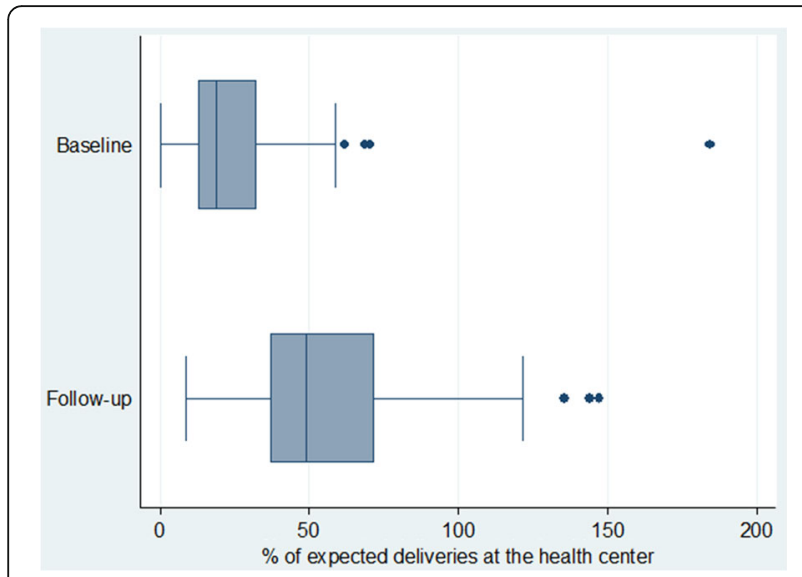

Fig. 2 Distribution of expected deliveries at the health centers by study period

maximum value then it can be concluded that all the components of the BEmONC interventions are being well implemented. However, if the BIS index score is not at the maximum or near the maximum value then individual items of the BIS index should be monitored to identify the areas with a gap.

There are several limitations with this study. First, the study used a nonexperimental program evaluation design; as such, the effect estimates could be confounded by unmeasured variables and the presence of possible selection bias. Second, the BIS index is the aggregation of 12 items. As a result, measurement error in one of the items would potentially introduce measurement error to the composite indicator. The observed association between BIS and the outcome variables would likely be inconsistent if the measurement error of the BIS is systematic.

Third, the change in data collection methods (paperbased during the baseline and mHealth-based during the follow-up) and different survey seasons between baseline and follow-up could bias the observed changes in the BIS index score and its components. However, these would be unlikely to affect the observed associations between the dependent and independent variables. Fourth, there is temporal ambiguity in the cross-sectional association between the met need for BEmONC and BIS index. Lastly, the BIS measure did not include all vital program input indicators. For example, although all health centers under study received post-training follow-

Table 6 Fixed-effect model estimates of effect of BIS score on health center delivery propensity

\begin{tabular}{llll}
\hline \multirow{2}{*}{ Independent variable } & \multicolumn{3}{l}{$\begin{array}{l}\text { Ordinary least-squares regression predicting } \\
\text { health center delivery }\end{array}$} \\
\cline { 2 - 4 } & Coefficient & $(95 \% \mathrm{Cl})$ & $p$-value \\
\hline BIS score & 4.5 & $(2.1,6.9)$ & $<.001$ \\
Constant & 21.3 & $(13.5,29.1)$ & $<.001$ \\
\hline
\end{tabular}

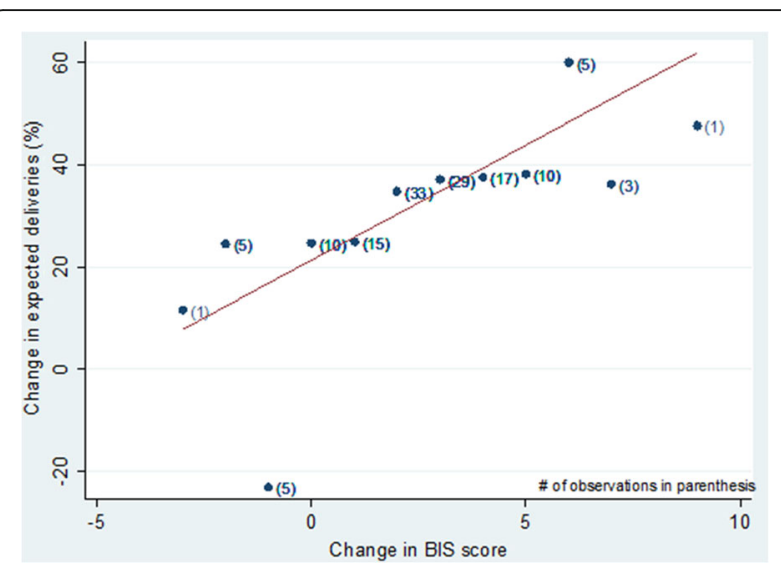

Fig. 3 Association between change in health center delivery rates and change in BIS score

up visits, the BIS index did not include whether any additional supervision and mentoring efforts were being provided as well as other supportive supervision efforts by hospitals and other partners, due to the problem of data verification as part of the BIS, which may have had a positive influence on the utilization of facility delivery and the met need for BEmONC.

We recommend further research on the quality of intrapartum care, the effect of BIS on the use of other maternal and newborn health services, equitable use of BEmONC services, and the cost of the BEmONC initiative. Provision of quality BEmONC services is an essential component for reducing maternal and newborn mortality rates [17]. As such, we recommend another study to investigate the effect of BIS on the obstetric complications case fatality rate, as well as on stillbirth and early neonatal death rates. Moreover, examining the effect of BIS on the utilization of other maternal and newborn health services is equally important. Improved uptake of BEmONC does not guarantee all women are using these services fairly; disadvantaged women might not access and use life-saving interventions. Disaggregated equity analysis of access to life-saving services would help health policy makers devise strategies to ensure equitable access to life-saving interventions for pregnant women who are beyond timely access to BEmONC and for poor women. Accordingly, we recommend other studies to examine the equitable use of BEmONC services by mothers. Furthermore, analyzing

Table 7 Ordinary least square model estimates for effect of BIS score on BEmONC met need

\begin{tabular}{llll}
\hline Independent variable & \multicolumn{2}{l}{ Ordinary least-squares regression predicting the } \\
& met need for BEmONC at health centers \\
\cline { 2 - 4 } & Coefficient & $(95 \% \mathrm{Cl})$ & $p$-value \\
\hline BIS score & 3.1 & $(1.6,4.6)$ & $<.001$ \\
Constant & -5.0 & $(-15.5,5.4)$ & .344 \\
\hline
\end{tabular}




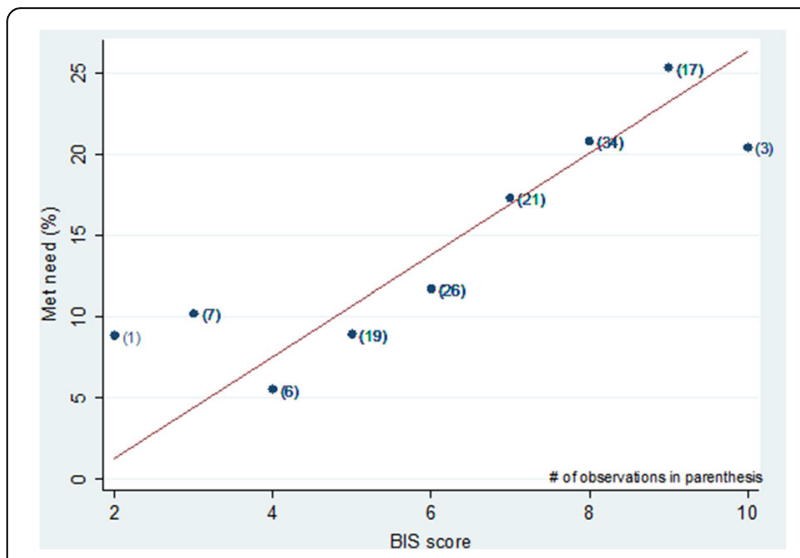

Fig. 4 Cross-sectional association between the met need for BEmONC at health centers and BIS score

the cost of the BEmONC initiative is critical for policymakers and program planners, as an evidence base to prioritize BEmONC and improve maternal and newborn health at the primary health care level.

Finally, we used equal weights for the 12 items to construct the BIS index, which might be questionable. Thus, we would like to recommend further research to examine whether and how to give differential weights to different items measuring the BIS scores at the primary care level.

\section{Conclusion}

The BEmONC initiative was effective in improving institutional deliveries and may have also improved the met need for BEmONC services. Potentially, the BIS index, including its components, could be used to monitor the implementation of BEmONC interventions.

\section{Additional files}

Additional file 1: Survey dataset. This is survey data and data dictionary we used for the analysis. The first sheet contains the data variables and values and the second sheet contains variable definitions (data dictionary). (XLSX $289 \mathrm{~kb})$

Additional file 2: Survey Questionnaire. Survey questionnaire we used to collect information from facilities. (DOCX $149 \mathrm{~kb}$ )

\section{Abbreviations}

BEmONC: Basic Emergency Obstetric and Newborn Care; BIS: BEmONC Implementation Strength; EmONC: Emergency Obstetric and Newborn Care; HIV: Human Immunodeficiency Virus; HSTP: Health Sector Transformation Plan; IV: Intravenous; LMIC: Low- and Middle-Income Countries; MMR: Maternal Mortality Ratio; NMR: Neonatal Mortality Rate; PHCU: Primary Health Care Unit: VDRL: Venereal Disease Research Laboratory test

\section{Acknowledgements}

We would like to thank USAID for funding the project and the surveys. The implementation of these surveys would not have been possible without the support of the Federal Ministry of Health and Regional Health Bureaus of Amhara, Oromia, the Southern National, Nationalities, and Peoples' Region, and Tigray regions. We take this opportunity to extend our gratitude to all the staff of the health centers for taking part in this project for the time they gave to respond to the survey questionnaires and provide us with valuable information. Finally, we would like to acknowledge our colleagues at The Last Ten Kilometers (L10 K) Project of JSI Research and Training Institute Inc. for their contributions at all stages of implementing this work and the interviewers and the supervisors for their hard work and dedication in accomplishing the field work on schedule.

\section{Funding}

United States Agency for International Development (USAID) funded the project with cooperative agreement number of GPO-I-00-06-00007-00 and AID-OAA-A-12-00047. The article write-up and publication fee was supported by the Bill \& Melinda Gates Foundation, Grant Number OPP1131042.

\section{Availability of data and materials}

The datasets used and analyzed during this study are included as an additional file to this article (Additional file 1).

\section{Authors' contributions}

GT: conceived the study design, interpretation, analysis, and drafting of the paper. AK: conceived the study design and methods, interpretation, analysis, and drafting parts of the paper. BA: conceived the study design, interpretation, analysis, and critical review. NZ, TW, and WB: conceived the study design, interpretation, and critical review. ZK and DW: interpretation and critical review. All authors read and approved the final manuscript.

\section{Ethics approval and consent to participate}

The ethical review committees of the Amhara, Oromia, SNNP, and Tigray regional health bureaus granted ethical clearance. The study participants (i.e., heads of the health centers and health care providers working in the maternity units) were informed about the purpose of the study and their right to opt-out or not to respond to questions. The study subjects provided informed verbal consent prior to any interview. The interviewer electronically marked the questionnaire as consent given if both the respondents agreed to be interviewed upon listening to the consent statement and then continued with the interview only after receiving and documenting the consent. The survey protocol submitted to the regional health bureaus ethical review committee included the study questionnaire and the consent statement with descriptions of the consent obtaining procedure which was approved by the committee. The name of the respondent was not recorded by the interviewer. Moreover, data collection did not interfere with their normal work with clients. The values, rights, and norms of the study subjects, enumerators and supervisors were respected.

\section{Competing interests}

The authors declare that they have no competing interests.

\section{Publisher's Note}

Springer Nature remains neutral with regard to jurisdictional claims in published maps and institutional affiliations.

\section{Author details}

${ }^{1}$ The Last Ten Kilometers (L10K) Project, JSI Research \& Training Institute, Inc., Addis Ababa, Ethiopia. ${ }^{2}$ The Last Ten Kilometers (L1OK) Project, JSI Research \& Training Institute, Inc., Washington DC, USA. ${ }^{3}$ IDEAS project, London School of Hygiene \& Tropical Medicine, London, UK. ${ }^{4}$ United States Agency for International Development (USAID), Addis Ababa, Ethiopia.

Received: 19 May 2017 Accepted: 19 April 2018

Published online: 02 May 2018

\section{References}

1. Nour NM. An introduction to maternal mortality. Rev Obstet Gynecol. 2008; 1(2):77-81.

2. Lawn JE, Blencowe H, Oza S, You D, Lee AC, Waiswa P, et al. Every newborn: progress, priorities, and potential beyond survival. Lancet (London, England). 2014:384(9938):189-205. https://doi.org/10.1016/s0140-6736(14)60496-7.

3. Paxton A, Maine D, Freedman L, Fry D, Lobis S. The evidence for emergency obstetric care. Int J Gynecol Obstet. 2005;88(2):181-93. https://doi.org/10. 1016/j.ijgo.2004.11.026. 
4. Lawn JE, Kerber K, Enweronu-Laryea C, Cousens S. 3.6 million neonatal deaths-what is progressing and what is not? Semin Perinatol. 2010;34(6): 371-86. https://doi.org/10.1053/j.semperi.2010.09.011.

5. The Partnership for Maternal Newborn \& Child Health. A global review of the key interventions related to Reproductive, Maternal, Newborn and Child Health (RMNCH). Geneva: PMNCH; 2011.

6. Cristina Rossi A, Mullin P. The etiology of maternal mortality in developed countries: a systematic review of literature. Arch Gynecol Obstet. 2012; 285(6):1499-503. https://doi.org/10.1007/s00404-012-2301-y.

7. Worku AG, Yalew AW, Afework MF. Maternal complications and women's behavior in seeking care from skilled providers in North Gondar, Ethiopia. PLoS ONE. 2013;8(3):e60171. https://doi.org/10.1371/journal.pone.0060171.

8. Ronsmans C, Graham WJ. Maternal mortality: who, when, where, and why. Lancet (London, England). 2006;368(9542):1189-200. https://doi.org/10.1016/ s0140-6736(06)69380-x.

9. Lassi ZS, Salam RA, Das JK, Bhutta ZA. Essential interventions for maternal, newborn and child health: background and methodology. Reprod Health. 2014;11(Suppl 1):S1-S. https://doi.org/10.1186/1742-4755-11-S1-S1.

10. WHO, UNICEF, UNFPA, World Bank Group, United Nations Population Division. Trends in maternal mortality: 1990 to 2015: estimates by WHO, UNICEF, UNFPA, World Bank Group and the United Nations Population Division. Geneva: World Health Organization; 2015.

11. UNICEF, World Health Organization, The World Bank, United Nations DESA/ Population Division. Levels \& Trends in child mortality. Report 2015. Estimates developed by the UN inter-agency Group for Child Mortality Estimation. New York: UNICEF; 2015

12. Admasu K, Haile-Mariam A, Bailey P. Indicators for availability, utilization, and quality of emergency obstetric care in Ethiopia, 2008. Int J Gynaecol Obstet. 2011;115(1):101-5. https://doi.org/10.1016/j.ijgo.2011.07.010

13. Girma M, Yaya Y, Gebrehanna E, Berhane Y, Lindtjorn B. Lifesaving emergency obstetric services are inadequate in south-west Ethiopia: a formidable challenge to reducing maternal mortality in Ethiopia. BMC Health Serv Res. 2013;13:459. https://doi.org/10.1186/1472-6963-13-459.

14. WHO. Strategies toward ending preventable maternal mortality (EPMM). Geneva: World Health Organization; 2015.

15. Chou D, Daelmans B, Jolivet RR, Kinney M, Say L. Ending preventable maternal and newborn mortality and stillbirths. Br Med J. 2015;351 https:// doi.org/10.1136/bmi.h4255.

16. Federal Ministry of Health (FMoH). Health sector transformation plan, 20162020. Addis Ababa: Federal Ministry of Health; 2015.

17. WHO, UNICEF, UNFPA, AMDD. Monitoring emergency obstetric care: a handbook. Geneva: World Health Organization; 2009.

18. Lindtjorn B, Mitiku D, Zidda Z, Yaya Y. Reducing maternal deaths in Ethiopia: results of an intervention Programme in Southwest Ethiopia. PLoS One. 2017;12(1):e0169304. https://doi.org/10.1371/journal.pone.0169304.

19. Hossain J, Ross SR. The effect of addressing demand for as well as supply of emergency obstetric care in Dinajpur, Bangladesh. Int J Gynaecol Obstet. 2006;92(3):320-8.

20. Lunze K, Higgins-Steele A, Simen-Kapeu A, Vesel L, Kim J, Dickson K. Innovative approaches for improving maternal and newborn health - a landscape analysis. BMC Pregnancy Childbirth. 2015;15:337. https:/doi.org/10.1186/s12884-015-0784-9.

21. Peters DH, Tran NT, Adam T. Implementation research in health: a practical guide. Geneva: Alliance for Health Policy and Systems Research, World Health Organization; 2013.

22. Hargreaves JRM, Goodman C, Davey C, Willey BA, Avan BI, Schellenberg JRMA. Measuring implementation strength: lessons from the evaluation of public health strategies in low- and middle-income settings. Health Policy Plan. 2016;31(7):860-7. https://doi.org/10.1093/heapol/czw001.

23. Victora CG, Black RE, Boerma JT, Bryce J. Measuring impact in the millennium development goal era and beyond: a new approach to largescale effectiveness evaluations. Lancet (London, England). 2011;377(9759): 85-95. https://doi.org/10.1016/s0140-6736(10)60810-0.

24. Scott $H$, Danel I. Accountability for improving maternal and newborn health. Best Pract Res Clin Obstet Gynaecol. 2016;36:45-56. https://doi.org/ 10.1016/j.bpobgyn.2016.05.009

25. Institute for International Programs. Measuring the strength of implementation of community case management of childhood illness within the catalytic initiative to save a million lives: working paper. Baltimore: Johns Hopkins School of Public Health; 2011
26. Schellenberg JA, Bobrova N, Avan Bl. Measuring implementation strength: literature review draft report. Working paper. London School of Hygiene and Tropical Medicine; 2012.

27. Paxton A, Bailey $P$, Lobis S, Fry D. Global patterns in availability of emergency obstetric care. Int J Gynecol Obstet. 2006;93(3):300-7. https:// doi.org/10.1016/j.ijgo.2006.01.030.

28. Fauveau V, Donnay F. Can the process indicators for emergency obstetric care assess the progress of maternal mortality reduction programs? An examination of UNFPA projects 2000-2004. Int J Gynaecol Obstet. 2006; 93(3):308-16. https://doi.org/10.1016/j.jijo.2006.01.031.

29. Hussein J, Kanguru L, Astin M, Munjanja S. The effectiveness of emergency obstetric referral interventions in developing country settings: a systematic review. PLoS Med. 2012;9(7):e1001264. https://doi.org/10.1371/journal.pmed. 1001264.

30. Nwolise $\mathrm{CH}$, Hussein J, Kanguru L, Bell J, Patel P. The effectiveness of community-based loan funds for transport during obstetric emergencies in developing countries: a systematic review. Health Policy Plan. 2015;30(7): 946-55. https://doi.org/10.1093/heapol/czu084.

31. Federal Ministry of Healt (FMoH). HSDP IV annual performance report 2012/ 13. Addis Ababa: Federal Ministry of Health; 2013.

32. Ethiopian Public Health Institute. Ethiopia Service Provision Assessment Plus (ESPA+) survey 2014. Addis Ababa: Ethiopian Public Health Institute, Federal Ministry of Health, and ICF International: Ethiopian Public Health Institute; 2014

33. Mowbray CT, Holter MC, Teague GB, Bybee D. Fidelity criteria: development, measurement, and validation. Am J Eval. 2003;24(3):315-40. https://doi.org/ 10.1177/109821400302400303.

34. Murray SF, Pearson SC. Maternity referral systems in developing countries: current knowledge and future research needs. Soc Sci Med. 2006;62(9): 2205-15. https://doi.org/10.1016/j.socscimed.2005.10.025.

35. Holmes W, Kennedy E. Reaching emergency obstetric care: overcoming the 'second delay'. Melbourne: Burnet Institute, on behalf of Compass, the Women's and Children's Health Knowledge Hub; 2010.

36. Thaddeus S, Maine D. Too far to walk: maternal mortality in context. Soc Sci Med. 1994;38(8):1091-110.

37. Dobility Inc. SurveyCTO. 2017. http://www.surveycto.com. Accessed 5 Oct 2017

38. Nunnally J, Bernstein I. Psychometric theory. 3rd ed. New York: McGraw-Hill; 1994

39. StataCorp. Stata: multivariate statistics reference manual: release 14. College Station: Stata Press; 2015.

40. Central Statistical Authority (CSA). 2007 Population and housing census of Ethiopia: administrative report. Addis Ababa: Central Statistical Authority; 2012.

41. StataCorp. Stata: release 14. Statistical software. College Station: Stata Press; 2015

42. Ethiopian Standard Agency. Ethiopian standard: health center requirements. 1st ed. Addis Ababa: Ethiopian Standard Agency; 2012.

\section{Ready to submit your research? Choose BMC and benefit from:}

- fast, convenient online submission

- thorough peer review by experienced researchers in your field

- rapid publication on acceptance

- support for research data, including large and complex data types

- gold Open Access which fosters wider collaboration and increased citations

- maximum visibility for your research: over $100 \mathrm{M}$ website views per year

At BMC, research is always in progress.

Learn more biomedcentral.com/submissions 